\title{
PEMBINAAN KADER PADA PROGRAM PERENCANAAN DAN PENCEGAHAN KOMPLIKASI (P4K) PADA IBU HAMIL
}

\author{
Erlinawati $^{1}$, Nila Kusumawati ${ }^{2}$ \\ ${ }^{1}$ Program Studi D III Kebidanan, Fakultas Ilmu Kesehatan, Universitas Pahlawan Tuanku Tambusai \\ e-mail : erlinawati@universitaspahlawan.ac.id \\ ${ }^{2}$ Program Studi S1 Kesehatan Masyarakat, Fakultas Ilmu Kesehatan, Universitas Pahlawan Tuanku Tambusai \\ nilakusumawati@universitaspahlawan.ac.id
}

\begin{abstract}
Abstrak
Angka kematian Ibu (AKI) dapat menggambarkan tingkat kesadaran perilaku hidup sehat, status gizi dan kesehatan ibu, kondisi kesehatan lingkungan, tingkat pelayanan kesehatan terutama untuk ibu hamil, pelayanan kesehatan waktu ibu melahirkan dan masa nifas. Untuk mempercepat penurunan AKI di Indonesia, pemerintah telah mengeluarkan berbagai macam kebijakan, seperti program perencanaan persalinan dan pencegahan komplikasi dengan stiker (P4K). Program yang dikeluarkan oleh Menteri Kesehatan pada tahun 2007 ini merupakan upaya terobosan dalam percepatan penurunan angka kematian ibu dan bayi baru lahir melalui kegiatan peningkatan akses dan kualitas pelayanan yang sekaligus merupakan kegiatan yang membangun potensi masyarakat khususnya kepedulian masyarakat untuk persiapan dan tindak lanjut dalam menyelamatkan ibu dan bayi baru lahir. Desa Ridan Permai merupakan salah satu desa di Kabupaten Kampar dengan masalah AKI. Menurut penelitian, kader mempunyai peranan yang cukup penting dalam pendampingan ibu hamil dengan harapan dapat menurunkan angka kematian ibu. Namun kenyataan di lapangan masih banyak kader yang belum memiliki pengetahuan yang memadai mengenai masalah kesehatan khususnya tentang kehamilan. Berdasarkan permasalahan tersebut, penyelesaian masalah yang telah dilakukan adalah memberikan penyuluhan tentang P4K. Metode pelaksanaan pengabdian masyarakat dilaksanakan secara kuantitatif dan kualitatif dengan metode FGD dan interview, lokasi di Posyandu Desa Ridan Permai pada tanggal 2, 12 dan 17 September 2019 dengan sasaran kader posyandu ibu hamil.

Kegiatan penyuluhan telah meningkatkan pengetahuan kader di desa Ridan Permai tentang P4K.
\end{abstract}

Kata Kunci : Angka Kematian Ibu, P4K, Persalinan, Pencegahan Komplikasi.

\begin{abstract}
The maternal mortality rate (MMR) can describe the level of awareness of healthy living behaviors, nutritional status and maternal health, environmental health conditions, the level of health services especially for pregnant women, health services during delivery and the postpartum period. To accelerate the reduction of MMR in Indonesia, the government has issued various policies, such as a birth planning program and prevention of complications with stickers $(P 4 K)$. The program issued by the Minister of Health in 2007 was a breakthrough in the acceleration of reducing maternal and newborn mortality through activities to improve access and quality of services which at the same time were activities that built community potential, especially community awareness for preparation and follow-up in saving mothers and newborn baby. Ridan Permai village is one of the villages in Kampar Regency with an AKI problem. According to research, cadres have an important role in assisting pregnant women with the hope of reducing maternal mortality. But the reality on the ground is that there are still many cadres who do not have sufficient knowledge about health issues, especially regarding pregnancy. Based on these problems, the solution to the problem that has been done is to provide counseling about P4K. Extension activities have increased the knowledge of cadres in Ridan Permai village about $P 4 K$.
\end{abstract}

Keywords : Maternal Mortality, P4K, Childbirth, Prevention of Complications. 


\section{PENDAHULUAN}

Kehamilan merupakan pengalaman yang sangat mengesankan bagi seorang perempuan terlebih lagi pada kehamilan pertama yang merupakan peristiwa kehidupan yang besar maknanya. Kondisi ini merupakan masa meningkatnya kewaspadaan dan terjadi perubahan besar. Kehamilan dan persalinan merupakan suatu hal yang alami akan tetapi bukan berarti tanpa resiko. Kehamilan dan persalinan memberikan kontribusi terhadapnya banyaknya Angka Kematian Ibu (AKI) dan Angka Kematian Bayi (AKB). AKI dapat menggambarkan tingkat kesadaran perilaku hidup sehat, status gizi dan kesehatan ibu, kondisi kesehatan lingkungan, tingkat pelayanan kesehatan terutama untuk ibu hamil, pelayanan kesehatan waktu ibu melahirkan dan masa nifas.

Program Perencanaan Persalinan \& Pencegahan Komplikasi (P4K) merupakan suatu kegiatan yang di fasilitasi oleh bidan di desa dengan peran aktif suami, keluarga dan masyarakat dalam merencanakan persalinan yang aman dan persiapan menghadapi komplikasi bagi ibu hamil, termasuk perencanaan penggunaan KB pasca persalinan dengan menggunakan stiker sebagai media notifikasi sasaran dalam rangka meningkatkan cakupan dan mutu pelayanan kesehatan bagi ibu dan bayi baru lahir.

Upaya agar program P4K tersebut dapat berjalan dengan baik dapat melibatkan semua unsur dalam masyarakat dan dilakukan secara terus menerus dan konsisten. Strategi yang dapat dilakukan adalah salah satunya dengan melibatkan kader posyandu. Kader-kader posyandu ini merupakan perpanjangan tangan pelayanan untuk kesehatan Ibu dan Anak di masyarakat. Kader berperan mendukung program $\mathrm{P} 4 \mathrm{~K}$ mulai perencanaan, pelaksanaan \& evaluasi serta pencatatan dan pelaporan. Kader yang sebagian besar merupakan anggota PKK, diharapkan dapat berperan sebagai pemberi informasi kesehatan kepada masyarakat, penggerak masyarakat untuk melaksanakan pesan-pesan kesehatan.

Kader mempunyai peranan yang cukup penting dalam pendampingan ibu hamil dengan harapan dapat menurunkan angka kematian ibu. Namun kenyataan di lapangan masih banyak kader yang belum memiliki pengetahuan yang memadai mengenai masalah kesehatan khususnya tentang kehamilan. Agar dapat melaksanakan peran tersebut dengan baik, kader perlu dibekali dengan pengetahuan yang memadai berkaitan dengan masalah kesehatan. Guna mencapai kader-kader yang berkualitas maka perlu dilakukan pembinaan bagi kader kesehatan mengenai pengetahuan maupun keterampilan khususnya tentang Kesehatan Ibu dan Anak. Untuk mewujudkan kader yang handal dan berkualitas menjadi tanggung jawab bersama dari berbagai pihak, tidak hanya dinas kesehatan ataupun pemerintahan setempat, akan tetapi perguruan tinggi juga mempunyai peran yang sangat penting dalam meningkatkan kualitas kader. Permasalahan yang dialami oleh mitra adalah kurangnya pengetahuan tentang Program Perencanaan Persalinan \& Pencegahan Komplikasi (P4K) dan tidak terpantaunya ibu hamil yang berisiko tinggi oleh kader.

Tujuan pengabdian masyarakat ini adalah meningkatnya pengetahuan, kesadaran dan pemahaman kader tentang P4K dan terlaksananya dan terdeteksinya ibu hamil yang berisiko tinggi melalui program $\mathrm{P} 4 \mathrm{~K}$ secara berkesinambungan.

\section{METODE}

Metode pelaksanaan pengabdian masyarakat dilaksanakan secara kuantitatif dan kualitatif dengan metode FGD dan interview, lokasi di Posyandu Desa Ridan Permai pada tanggal 2, 12 dan 17 September 2019. Sasaran kader posyandu ibu hamil, sumber data ; Bidan koordinator Desa Ridan Permai dengan tahapan :

1) FGD dengan bidan koordinator terkait permasalahan pada ibu hamil di Desa Ridan Permai

2) Melakukan peningkatan pengetahuan kader melalui penyuluhan tentang Program Perencanaan Persalinan \& Pencegahan Komplikasi (P4K) dan ibu hamil risiko tinggi melalui penyuluhan

3) Pengabdi, Bidan koordinator bersama kader melakukan kontak dengan ibu hamil, suami dan keluarga. 
4) Sosialisasi P4K dengan stiker kepada kader dan praktik penempelan stiker pada ibu hami yang berisiko tinggi, kemudian Stiker dilepaskan sampai 40 hari pasca persalinan dimana ibu dan bayi yang dilahirkan aman dan selamat

5) Mengadakan pertemuan bulanan di tingkat desa ( contoh : posyandu, forum desa siaga) agar pelaksanaan program $\mathrm{P} 4 \mathrm{~K}$ berjalan secara berkesinambungan

\section{HASIL DAN PEMBAHASAN}

\section{Hasil Pengabdian Masyarakat}

Kegiatan pengabdian ini dilakukan di Posyandu Tunas Harapan Desa Ridan PermaiPermai Kecamatan Bangkinang Kabupaten Kampar pada tanggal 2, 12 dan 17 September 2019. Kegiatan ini diikuti oleh 10 kader ibu hamil di Desa Ridan PermaiPermai.

Materi pertama yang diberikan yaitu pengetahuan kader tentang program P4K. Materi kedua resiko tinggi pada ibu hamil.

Tabel 1 Pengetahuan kader sebelum dan sesudah diberikan penyuluhan

\begin{tabular}{|c|l|c|c|c|c|}
\hline \multirow{2}{*}{ No } & \multirow{2}{*}{ Kategori } & \multicolumn{2}{|c|}{ Sebelum } & \multicolumn{2}{c|}{ Sesudah } \\
\cline { 3 - 6 } & & $\mathrm{n}$ & $\%$ & $\mathrm{n}$ & $\%$ \\
\hline 1 & Rendah & 8 & 80 & 0 & 0 \\
\hline 2 & Sedang & 2 & 20 & 2 & 20 \\
\hline 3 & Tinggi & 0 & 0 & 8 & 80 \\
\hline \multicolumn{2}{|c|}{ Jumlah } & 10 & 100 & 10 & 100 \\
\hline
\end{tabular}

Berdasarkan Tabel 1 dapat dilihat pengetahuan ibu di Desa Ridan PermaiPermai sebelum diberikan penyuluhan mayoritas $(80 \%)$ memiliki pengetahuan rendah. Sedangkan sesudah diberikan penyuluhan terjadi peningkatan pengetahuan, dimana mayoritas $(80 \%)$ termasuk kategori berpengetahuan tinggi.

\section{Pembahasan}

Berdasarkan Tabel 6.1 dapat dilihat pengetahuan ibu di Desa Ridan PermaiPermai sebelum diberikan penyuluhan mayoritas $(80 \%)$ memiliki pengetahuan rendah. Sedangkan sesudah diberikan penyuluhan terjadi peningkatan pengetahuan, dimana mayoritas (80\%) termasuk kategori berpengetahuan tinggi. Dapat disimpulkan bahwa penyuluhan yang dilakukan pengabdi dikatakan efektif.

Program P4K ini peran serta masyarakat, kader dan meliputi; memberikan penyuluhan yang berhubungan dengan kesehatan ibu (tanda bahaya kehamilan, persalinan dan sesudah melahirkan), membantu bidan dalam mendata jumlah ibu hamil di wilayah desa binaan, membantu bidan dalam memfasilitasi keluarga untuk menyepakati isi stiker termasuk KB sesudah melahirkan, bersama-sama membahas tentang masalah calon donor darah, transportasi dan pembiayaan untuk membantu dalam menghadapi kegawatdaruratan pada waktu hamil, bersalin dan sesudah melahirkan, menganjurkan suami untk mendampingi pada pemeriksaan kehamilan, persalinan dan sesudah melahirkan, serta menganjurkan pemberian ASI eksklusif pada bayi sampai usia 6 bulan.

Program Perencanaan Persalinan dan Pencegahan Komplikasi (P4K) adalah suatu kegiatan yang difasilitasi oleh bidan di desa dalam rangka peningkatan peran aktif suami, keluarga dan masyarakat dalam merencanakan persalinan yang aman dan persiapan menghadapi komplikasi bagi ibu hamil, termasuk perencanaan penggunaan kontrasepsi pasca persalinan dengan menggunakan stiker sebagai media notifikasi sasaran dalam rangka meningkatkan cakupan dan mutu pelayanan kesehatan bagi ibu dan bayi baru lahir (Depkes, 2009). Dari hasil pengabdian output yang dihasilkan adalah : 
1) Semua ibu hamil terdata dan rumahnya tertempel stiker

2) Bidan memberikan pelayanan antenatal sesuai standar

3) Ibu hamil dan keluarganya mempunyai rencana persalinan termasuk KB yang dibuat bersama dengan penolong persalinan

4) Bidan menolong persalinan sesuai standar

5) Bidan memberikan pelayanan nifas sesuai standar

6) Keluarga menyiapkan biaya persalinan, kebersihan dan kesehatan lingkungan (sosial budaya)

7) Adanya keterlibatan tokoh masyarakat baik formal maupun non formal dan forum peduli KIA/Pokja Posyandu dalam rencana persalinan termasuk KB pasca persalinan sesuai dengan perannya masing-masing.

\section{SIMPULAN}

Pengetahuan kader posyandu di Desa Ridan PermaiPermai sebelum diberikan penyuluhan diberikan penyuluhan mayoritas $(80 \%)$ memiliki pengetahuan rendah. Sedangkan sesudah diberikan penyuluhan terjadi peningkatan pengetahuan, dimana mayoritas $(80 \%)$ termasuk kategori berpengetahuan tinggihampir separuh (45\%) termasuk kategori sedang dan 25\% termasuk kategori tinggi.

\section{SARAN}

Kepada pengabdi selanjutnya disarankan agar melakukan pemantauan terhadap kader secara berkelanjutan agar program pebgabdian yang telah dilakukan dapat tercapai lebih maksimal.

\section{UCAPAN TERIMA KASIH}

Penulis mengucapkan terimaksih kepada Universitas Pahlawan Tuanku Tambusai yuang telah memberikan dukungan finansial kegiatan pengabdian masyarakat ini.

\section{DAFTAR PUSTAKA}

Bobak, Jensen, Zalar. (2002). Maternity and Gynecologycal Care, St. Lois, Baltimore, Toronto, The C.V. Mosby Co

Bobak, Jensen, Zalar. (2005). Keperawatan Maternitas, Edisi 4. Jakarta : EGC

Depkes RI dan JICA. (2007). Pegangan Fasilitator Kelas Ibu Hamil. Jakarta : Depkes RI

Depkes RI dan JICA. (2008). Buku Kesehatan Ibu dan Anak. Jakarta : Depkes RI

Depkes RI. (2006). Modul Asuhan Persalinan Normal Pencegahan dan Penanganan Malaria selama Kehamilan, Buku Acuan Bagi Bidan di Desa dan Perawat ANC. Jakarta

Depkes RI. (2008). Buku Pelatihan Konseling Menyusui. Jakarta : Depkes RI

Depkes RI. (2004). Buku Pedoman Nasional Pencegahan Penularan HIV dari Ibu ke Bayi. siha.depkes.go.id

Notoatmodjo, S. (2000). Pendidikan dan Perilaku Kesehatan. Jakarta: Rineka Cipta. Sitoayu, L. (2018). Pemanfaatan Bahan Makanan Sederhana menjadi Gizi Seimbang. Jurnal Abdimas (4) 2: 230-234. 